\title{
FANCD2 Western blot as a diagnostic tool for Brazilian patients with Fanconi anemia
}

\author{
D.V. Pilonetto ${ }^{1}$, N.F. Pereira ${ }^{1}$, M.A. Bitencourt ${ }^{2}$, N.I.R. Magdalena², E.R. Vieira ${ }^{1}$, \\ L.B.A. Veiga ${ }^{1}$, I.J. Cavalli ${ }^{1}$, R.C. Ribeiro ${ }^{3}$ and R. Pasquini ${ }^{2}$ \\ ${ }^{1}$ Laboratório de Imunogenética, Hospital de Clínicas, Universidade Federal do Paraná, Curitiba, PR, \\ Brasil \\ ${ }^{2}$ Ambulatório de Anemia de Fanconi, Hospital de Clínicas, Universidade Federal do Paraná, Curitiba, \\ PR, Brasil \\ 3International Outreach Program, St. Jude Children's Research Hospital, Memphis, TN, USA \\ Correspondence to: D.V. Pilonetto, Laboratório de Imunogenética, Hospital de Clínicas, UFPR, Rua \\ Padre Camargo, 280, 10 andar, 80060-240 Curitiba, PR, Brasil \\ Fax:+55-41-3360-1801. E-mail: danivp@ufpr.br
}

\begin{abstract}
Fanconi anemia is a rare hereditary disease showing genetic heterogeneity due to a variety of mutations in genes involved in DNA repair pathways, which may lead to different clinical manifestations. Phenotypic variability makes diagnosis difficult based only on clinical manifestations, therefore laboratory tests are necessary. New advances in molecular pathogenesis of this disease led researchers to develop a diagnostic test based on Western blot for FANCD2. The objective of the present study was to determine the efficacy of this method for the diagnosis of 84 Brazilian patients with Fanconi anemia, all of whom tested positive for the diepoxybutane test, and 98 healthy controls. The FANCD2 monoubiquitinated isoform (FANCDS+/FANCD2L-) was not detected in 77 patients (91.7\%). In 2 patients (2.4\%), there was an absence of both the monoubiquitinated and the non-ubiquitinated proteins (FANCD2S-/FANCD2L-) and 5 patients (5.9\%) had both isoforms (FANCD2S+/FANCD2L+). This last phenotype suggests downstream subtypes or mosaicism. All controls were diepoxybutane negative and were also negative on the FANCD2 Western blot. The Western blot for FANCD2 presented a sensitivity of $94 \%$ (79/84) and specificity of 100\% (98/98). This method was confirmed as an efficient approach to screen Brazilian patients with deleterious mutations on FANCD2(FANCD2S-/FANCD2L-) or other upstream genes of the FA/BRCA pathway (FANCDS+/FANCD2L-), to confirm the chromosome breakage test and to classify patients according to the level of FA/BRCA pathway defects. However, patients showing both FANCD2 isoforms (FANCD2S+/FANCD2L+) require additional studies to confirm mutations on downstream Fanconi anemia genes or the presence of mosaicism.
\end{abstract}

Key words: Fanconi anemia; FANCD2 Western blot; Diepoxybutane test; Monoubiquitination; Immunoblotting

Research supported in part by the International Outreach Program, St. Jude Children's Research Hospital, Memphis, TN, USA.

Received July 17, 2008. Accepted January 20, 2009

\section{Introduction}

Fanconi anemia (FA) is a recessive disease, with either an autosomal or X-linked pattern of inheritance, characterized by chromosomal instability and malformations, with frequent progressive marrow failure and predisposition to develop leukemia and solid tumors later in life (1-3).

An increasing number of FA genes have been identified and their allelic products are interconnected with other DNA damage response proteins involved with ge- nomic stability and tumorigenesis $(4,5)$. Thirteen disease causing genes and their respective complementation groups or subtypes have been identified so far: FANCA (FA-A), FANCB (FA-B), FANCC (FA-C), FANCD1/BRCA2 (FA-D1), FANCD2(FA-D2), FANCE(FA-E), FANCF(FA-F), FANCG/XRCC9(FA-G), FANCI/KIAA1794(FA-I), FANCJI BACH1/BRIP1 (FA-J), FANCL/PHF9 (FA-L), FANCM/Hef (FA-M), FANCN/PALB2 (FA-N) (6-19). Although most of FA patients have mutations in genes corresponding to subtypes FA-A (66\%), FA-C (10\%) and FA-G (9\%), the wide genetic and clinical heterogeneity makes difficult to 
have a comprehensive diagnosis of this disease $(20,21)$.

Considerable progress in the field of FA pathogenesis has resulted from extensive research concerning defects involving FA genes, but the precise molecular role remains elusive. A general model has been proposed for the FA pathway based on the response to DNA after exposure of cells to genotoxic stress or following replication arrests $(22,23)$. In brief, eight of the cloned FA genes encode for proteins (FANCA, B, C, E, F, G, L, M), which are part of a large nuclear core complex with multiple subunits and E3 ubiquitin ligase activity $(5,24)$. The activation of this complex induced by DNA replication or by DNA-damage results in monoubiquitination of FANCD2, which moves into areas of damaged chromatin to interact with downstream $F A$ members (FANCD1/BRCA2, FANCJ, FANCN) and other DNA-repair proteins such as BRCA1 and RAD51. FANCD2 is the central protein that connects the FA/BRCA pathway to the homologous recombination-mediated DNA repair (18, $19,23,25-28)$. The recently identified $\mathrm{FANCI}$ protein associates with FANCD2 and is the second monoubiquitinated component of the FA pathway $(14,29)$.

A distinctive feature of FA cells is their inability to repair DNA damage induced by DNA interstrand cross-linking agents such as mitomycin C or diepoxybutane (DEB), which are often used as standard diagnostic tests $(30,31)$. As mentioned above, a critical regulatory event in the FA/ BRCA pathway is the monoubiquitination of FANCD2 at lysine 561 (22). A point mutation at amino acid residue 561 , which is the site of monoubiquitination, abolishes its ability to correct sensitivity to these chromosome breakage agents. Mutations in any of the upstream FA genes also result in disruption of the FA/BRCA pathway leading to inefficient repair of the lesions and causing many of the clinical and cellular features of FA $(23,26)$.

On the basis of these considerations, Shimamura et al. (32) developed a diagnostic screen test for the integrity of the FA pathway. This test is based on the Western blot for FANCD2 where both isoforms of this central protein (monoubiquitinated and non-ubiquitinated) can be distinguished. Furthermore, Soulier et al. (33) proposed an evaluation strategy to detect functional reversion in peripheral blood lymphocytes (PBLs) and to classify FA patients. These investigators showed that comparison of fibroblasts and PBLs using FANCD2 Western blots permits the detection of somatic mosaicism.

Somatic mosaicism in hematopoietic FA cells comes from reversion of inherited deleterious mutations to the normal wild-type allele and it results in the presence of both normal and mutant hematopoietic cells in a single individual (34).

An improved diagnostic screen test is essential since
FA patients may present unique characteristics requiring frequent monitoring and early specific therapeutic interventions. The objective of the present study was to evaluate the efficacy of the Western blot for FANCD2 for the diagnosis of $F A$ in Brazilian patients and to classify these patients according to the level of FA/BRCA pathway defects. We compared FANCD2 phenotypes provided by Western blot to the "gold standard" DEB test parameters, such as chromosomal breakage rate and percent of somatic reversion.

\section{Subjects and Methods}

\section{Subjects}

Eighty-four patients ( 75 probands and 9 siblings) referred to the Fanconi Outpatient Clinic (Hospital de Clínicas, Universidade Federal do Paraná) from July 2004 to November 2006 were enrolled in the study. All patients were diagnosed as having FA based on clinical manifestations and cellular hypersensitivity to DEB. In the group of 84 patients, 49 (58.3\%) were female; median age at the time of study was 11 years ( 2 to 34 years), median age at the time of diagnosis was 7 years ( 3 months to 30 years) and age at the beginning of marrow failure was 8.5 years (1 to 24 years).

The hematological status of the patients at the time of this study was defined according to the severity of the bone marrow failure: 13 patients $(15.5 \%)$ were in stage I $=$ no marrow failure (platelets $>100,000 / \mu \mathrm{L}$, neutrophil $>1000 / \mu \mathrm{L}$, hemoglobin level $>10 \mathrm{~g} / \mathrm{dL}), 38$ patients $(45.2 \%)$ were in stage $\mathrm{II}=$ early marrow failure (at least one of the following: platelets $<100,000 / \mu \mathrm{L}$ and $>20,000 / \mu \mathrm{L}$, neutrophil $<1000 / \mu \mathrm{L}$ and $>500 / \mu \mathrm{L}$, hemoglobin $<10 \mathrm{~g} / \mathrm{dL}$, no transfusions or $<20$ platelets or red cells transfusions) and 33 patients $(39.3 \%)$ were in stage $\mathrm{III}=$ advanced marrow failure (at least one of the following: platelets below $20,000 / \mu \mathrm{L}$, neutrophil $<500 / \mu \mathrm{L}$, requiring regular transfusions of red cells or platelets) $(2,35)$. The extent of malformations was assessed according to the number of anatomic sites involved: absent (no sites involved) in 10 patients (11.9\%), limited (<3 sites) in 46 patients $(54.8 \%)$ and extensive (3 or more sites involved, at least one deep organ) in 28 patients (33.3\%) $(2,35)$.

Ninety-eight healthy volunteers with normal blood cell counts, selected among staff of Hospital de Clínicas, Universidade Federal do Paraná, and blood donors from Hospital de Clínicas Blood Bank, were included as controls. Fifty-eight females and 40 males were recruited to match gender with patients. Their age ranged from 17 to 58 years (median $=37$ years). The local Ethics Committee approved this study and the peripheral blood samples 
from patients and control subjects were obtained after written informed consent.

\section{Methods}

FANCD2 Western blot. This procedure was previously described by Garcia-Higuera et al. (22) and Shimamura et al. (32) as follows:

Isolation of mononuclear cells and primary lymphocytes culture. Peripheral blood mononuclear cells from patients and normal controls were isolated using a FicollPaque gradient (GE Healthcare, United Kingdom). Cells were cultured in RPMI 1640 (Gibco, USA) supplemented with $15 \%$ fetal calf serum (FCS), $2 \mathrm{mM}$ L-glutamine, $1 \%$ penicillin and streptomycin and stimulated with phytohemagglutinin (Sigma/Aldrich, USA) for $72 \mathrm{~h}$. HeLa cells were grown in Dulbecco's modified Eagle's medium (Gibco) supplemented with 15\% FCS. All cell cultures were maintained in a humidified incubator containing $5 \% \mathrm{CO}_{2}$ at $37^{\circ} \mathrm{C}$.

Western blot and detection of monoubiquitinated FANCD2. After $72 \mathrm{~h}$ of culture, phytohemagglutinin-stimulated mononuclear cells were treated with lysis buffer (50 $\mathrm{mM}$ Tris- $\mathrm{HCl}, 1 \%$ Nonidet-P40, $0.1 \%$ sodium deoxycholate, $0.15 \mathrm{M} \mathrm{NaCl}, 10 \mathrm{mM}$ sodium pyrophosphate, $10 \mathrm{mM}$ sodium fluoride, and protease inhibitors) adjusted to a final concentration of $50-100 \mu \mathrm{g}$ of total protein in sample buffer (50 mM Tris- $\mathrm{HCl}, 86 \mathrm{mM}$ 2-mercaptoethanol, 2\% sodium dodecyl sulfate (SDS), bromophenol blue), heated for $5 \mathrm{~min}$ at $96^{\circ} \mathrm{C}$ and loaded on $7 \%$ SDS polyacrylamide gel for electrophoresis. Proteins were transferred to nitrocellulose using a submerged transfer apparatus (BioRad, USA) and transfer buffer (25 mM Tris base, $200 \mathrm{mM}$ glycine, containing $20 \%$ methanol). The nitrocellulose membrane was blocked with $5 \%$ nonfat dried milk in TBS-T (50 mM Tris- $\mathrm{HCl}, 150$ mM NaCl, 0.1\% Tween 20) and incubated for $2 \mathrm{~h}$ with primary anti-FANCD2 mouse monoclonal antibody (FI17 Santa Cruz, USA) diluted 1:200 or anti-BRCA2 rabbit monoclonal antibody (Ab2; Calbiochem/Immunochemicals, USA) at 1:100 dilution, followed by incubation with the respective secondary antibody (BioRad) linked to horseradish peroxidase. Chemiluminescence was used for detection based on peroxidase oxidation of diacylhydrazide (luminol) liberated from hydrogen peroxide under alkaline conditions (kit ECL RPN2109 ${ }^{\circledR}$, GE Healthcare). Blots were drained and exposed to radiographic films, which showed the presence or absence of bands corresponding to each of the FANCD2 isoforms. The short or small band (S) corresponds to the non-ubiquitinated protein and the long or large $(L)$ band refers to the monoubiquitinated FANCD2 protein. Interpretation of the phenotypes provided by the patterns of the FANCD2 bands is shown in Table $1(22,32)$.

\section{Chromosome breakage test - diepoxybutane}

The DEB test described by Auerbach et al. was used as reference for Fanconi anemia diagnosis $(30,31)$. At least 50 cells (25 metaphases with DEB and 25 without DEB) were analyzed for each sample. Results were reported as breaks per cell based on the total number of chromosomal breaks divided by the total number of metaphases analyzed. Rates of breaks per metaphase greater than 1.06 were considered positive for FA. This reference value used by the Cytogenetics Laboratory at Hospital de Clínicas, Universidade Federal do Paraná is that established by IFAR (International Fanconi Anemia Register) (31). Another parameter provided by the DEB test is the percentage of reverted cells, which are cells without breaks, i.e., DEBresistant PBLs. The percent of reverted cells is calculated as follows: (total number of cells analyzed - number of cells with breaks) $\times 100 /$ total number of cells analyzed. Although the presence of large numbers of cells without breaks suggests reversion, this phenomenon must be confirmed by investigating a non-hematopoietic tissue, such as skin fibroblasts, where a positive DEB test is expected.

Table 1. Interpretation of FANCD2 Western blot phenotypes.

FANCD2 phenotypes Interpretation

FANCD2S+/FANCD2L- Mutation on upstream genes of the FA/BRCA pathway: core complex (FANCA, B, C, E, F, G, L, M) or FANCI

FANCD2S-/FANCD2L- Mutation on FANCD2 that codes for the central protein of the FA/BRCA pathway

FANCD2S+/FANCD2L+ One of the following: Mutations on downstream genes of the FA/BRCA pathway: FANCD1/BRCA2, FANCJ, FANCN, or other genes not identified

Somatic mosaicism

Another chromosome breakage disease

Non-Fanconi/normal phenotype

FANCD2S = band corresponding to isoform $S$ (short or small) of the protein FANCD2. FANCD2L = band corresponding to isoform $L$ (long or large) of monoubiquitinated FANCD2 protein. 
Statistical analysis

The sensitivity and specificity of the Western blot for FANCD2 were estimated considering the DEB test as the "gold standard" reference. The $95 \% \mathrm{Cl}$ was calculated to determine the proportion of inconclusive results by the Western blot. Comparison of FANCD2 phenotypes to DEB test results (breakage rates and percent of somatic reversion) was performed by the non-parametric Mann-Whitney test using the Statistica version 5.1 software (36). A P value of less than 0.05 was considered to be statistically significant.

\section{Results and Discussion}

Results of Western blot for FANCD2 of Brazilian patients with Fanconi anemia and healthy controls are shown in Table 2. All 98 healthy controls were FANCD2S+/ FANCD2L+ and negative in the DEB test. The 84 DEB+ patients were classified into three phenotypic classes. The majority of patients $(77 / 84 ; 91.7 \%)$, including 68 probands and their respective 9 siblings, were FANCD2S+/ FANCD2L-. This result is in agreement with worldwide data showing that complementation groups of the core complex represents more than $90 \%$ of the cases $(20,21)$. Soulier et al. (33) identified this phenotype in $89 \%$ of the patients (47 of 53) by FANCD2 Western blot on PBLs and on skin fibroblasts.

FANCD2S+/FANCD2L- phenotype denotes deleterious mutations in any of the genes coding for core complex proteins (FANCA, B, C, E, F, G, L, and M). FANCD2S+/ FANCD2L- patients may also belong to the FA-I complementation group. This subtype has been recently identified and it is likely to function between the core complex and FANCD2(14).

Upstream defects on the FA/BRCA pathway result in

Table 2. Frequency of FANCD2 phenotypes determined by Western blot of cells of patients with Fanconi anemia and normal controls.

\begin{tabular}{llcc}
\hline DEB test & $\begin{array}{l}\text { FANCD2S/FANCD2L } \\
\text { phenotypes }\end{array}$ & $\begin{array}{c}\text { Patients } \\
(\mathrm{N}=84)\end{array}$ & $\begin{array}{c}\text { Controls } \\
(\mathrm{N}=98)\end{array}$ \\
\hline Positive & FANCD2S+/FANCD2L- & $77(91.7 \%)$ & - \\
Positive & FANCD2S-/FANCD2L- & $2(2.4 \%)$ & - \\
Positive & FANCD2S+/FANCD2L+ & $5(5.9 \%)$ & - \\
Negative & FANCD2S+/FANCD2L+ & - & $98(100 \%)$
\end{tabular}

Data are reported as number of patients and percent. FANCD2S = band corresponding to isoform S (short or small) of the protein FANCD2. $F A N C D 2 L=$ band corresponding to isoform $L$ (long or large) of monoubiquitinated FANCD2 protein. $\mathrm{DEB}=$ diepoxybutane. the absence of the large isoform FANCD2L (Figure 1). Following DNA damage, the core complex is required for monoubiquitination of FANCD2, which is the central protein of FA/BRCA pathway. Studies by Smogorzewska et al. (14) and Sims et al. (29) suggest that previous monoubiquitination of $\mathrm{FANCl}$ is important for subsequent FANCD2 monoubiquitination. The activated isoform of FANCD2 (FANCD2L) is targeted to the nuclear foci where it functions in concert with BRCA1/BRCA2/RAD51 at the sites of DNA damage and repair $(23,25,37)$.

In 2 of 84 patients (2.4\%), neither FANCD2S nor FANCD2L was detected in distinct samples obtained at different times (Figure 1). Western blot for BRCA2 as well as Ponceau staining were performed to exclude protein degradation on samples that showed absence of both isoforms (FANCD2S-/FANCD2L-). These data are similar to those of Soulier et al. (33) who found absence of FANCD2 bands in 5.7\% FA patients. This phenotype suggests mutations on FANCD2 that may either alter its level of expression or result on a dysfunctional protein.

Presence of both FANCD2 isoforms was found in 5 of $84(5.9 \%)$ patients (Figure 1). FANCD2S+/FANCD2L+ phenotype in patients with a positive chromosome breakage test and FA clinical features suggests deleterious mutation on any of the genes functioning downstream of FANCD2 monoubiquitination. Three complementation groups corresponding to downstream proteins, that play their role after FANCD2 activation, have been identified (FANCD1/ BRCA2, FANCJ and FANCN) $(9,15,19,28)$. Western blots for BRCA2 were performed on FANCD2S+/FANCD2L+ patients and all of them showed normal expression of this protein. This suggests involvement of other downstream subtypes such as FA-J or FA-N, although molecular investigation is required to definitely exclude defects on BRCA2 gene, which may translate into dysfunctional protein. Previous studies showed that patients belonging to subtypes FAD1/BRCA2 or FA-N had rapid and severe evolution of the disease with high risks of childhood solid tumors, acute myeloid leukemia and other malignancies $(18,38)$.

Another explanation for DEB+ patients with both FANCD2 isoforms is the presence of mosaicism, i.e., the co-existence of genetically distinct hematopoietic populations probably due to reversion of inherited deleterious mutations to wild type $(34-39,40)$. Clinical significance of somatic mosaicism is not well understood. Despite the suggestion of a milder phenotype in these patients, reversion is frequently associated with bone marrow failure and leukemia (39). The presence of a significant number of reverted cells can mask FA diagnostic tests giving ambiguous or false-negative results $(33,40)$. Somatic mosaicism can hide mutations on FANCD2 itself or on 
upstream FA genes by a high number of reverted hematopoietic cells that show an upper ubiquitinated band on the Western blot. In 4 of 5 patients enrolled in this study, the DEB resistant PBLs (reverted cells) comprised more than $50 \%$ of cells analyzed $(60,68,73.4$, and $76.0 \%)$. Due to unavailability of skin fibroblasts, DEB+ patients showing FANCD2S+/FANCD2L+ phenotype could not be investigated further. The lack of information on non-he- matopoietic tissue did not allow the conclusion about the level of disruption on the FA/BRCA pathway in these patients. One in 5 patients had only $4 \%$ of reverted cells, which is more suggestive of a defect on genes involved in steps downstream the FANCD2 activation.

The distribution of patients according to DEB test parameters, chromosomal breakage rate and percent of somatic reversion are reported in Figure 2. Patients were

Figure 1. Western blot for FANCD2 can distinguish the ubiquitinated and non-ubiquitinated isoforms of FANCD2. Protein extracts of HeLa cell line, and lymphocytes isolated from healthy controls and from Falconi anemia (FA) patients were submitted to phytohemagglutinin stimulation and to Western blot with a mouse monoclonal anti-

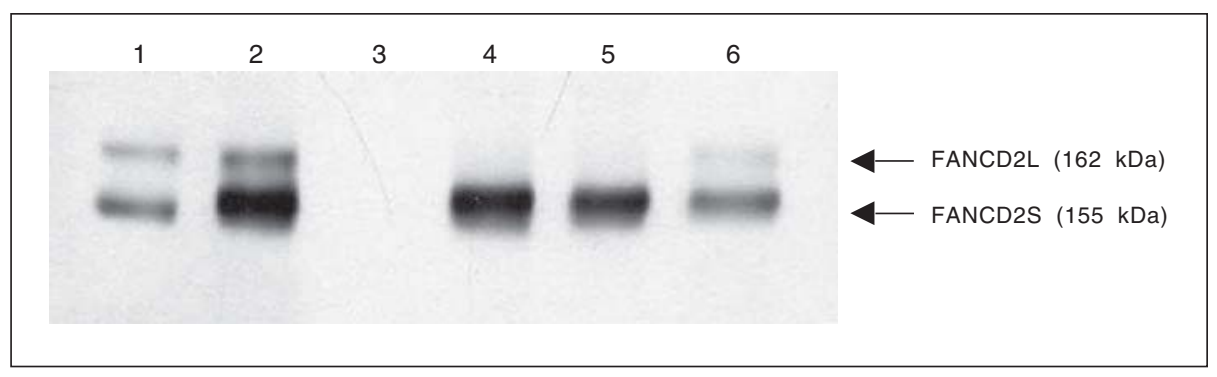
body to FANCD2. Lane 1 is a

HeLa cell line and lane 2 lymphocytes from a healthy control; both showed a normal distribution of FANCD2 proteins, ubiquitinated long form (FANCD2L) seen as an upper band that is $7 \mathrm{kDa}$ larger than the unmodified short form (FANCD2S). In lane 3 no FANCD2 protein was detected in the whole lymphocyte extract from an FA patient suggesting mutations on FANCD2 that may either alter its level of expression or result on a dysfunctional protein, but this must be confirmed by molecular analysis. In lanes 4 and 5 , only the unmodified short form (FANCD2S) was detected in the lymphocyte extract from these two patients, compatible with the hypothesis of mutations in any one of the FA genes that correspond to proteins of the nuclear core complex or mutations in the $\mathrm{FANCl}$ gene. In lane 6 , both the ubiquitinated long (FANCD2L) and the unmodified short (FANCD2S) isoforms were detected in the lymphocyte extract from the patient. This phenotype is consistent with either mutation in one of the genes coding for downstream proteins (FANCJ, FANCD1/BRCA2 and FANCN) or somatic mosaicism, which requires further investigation.

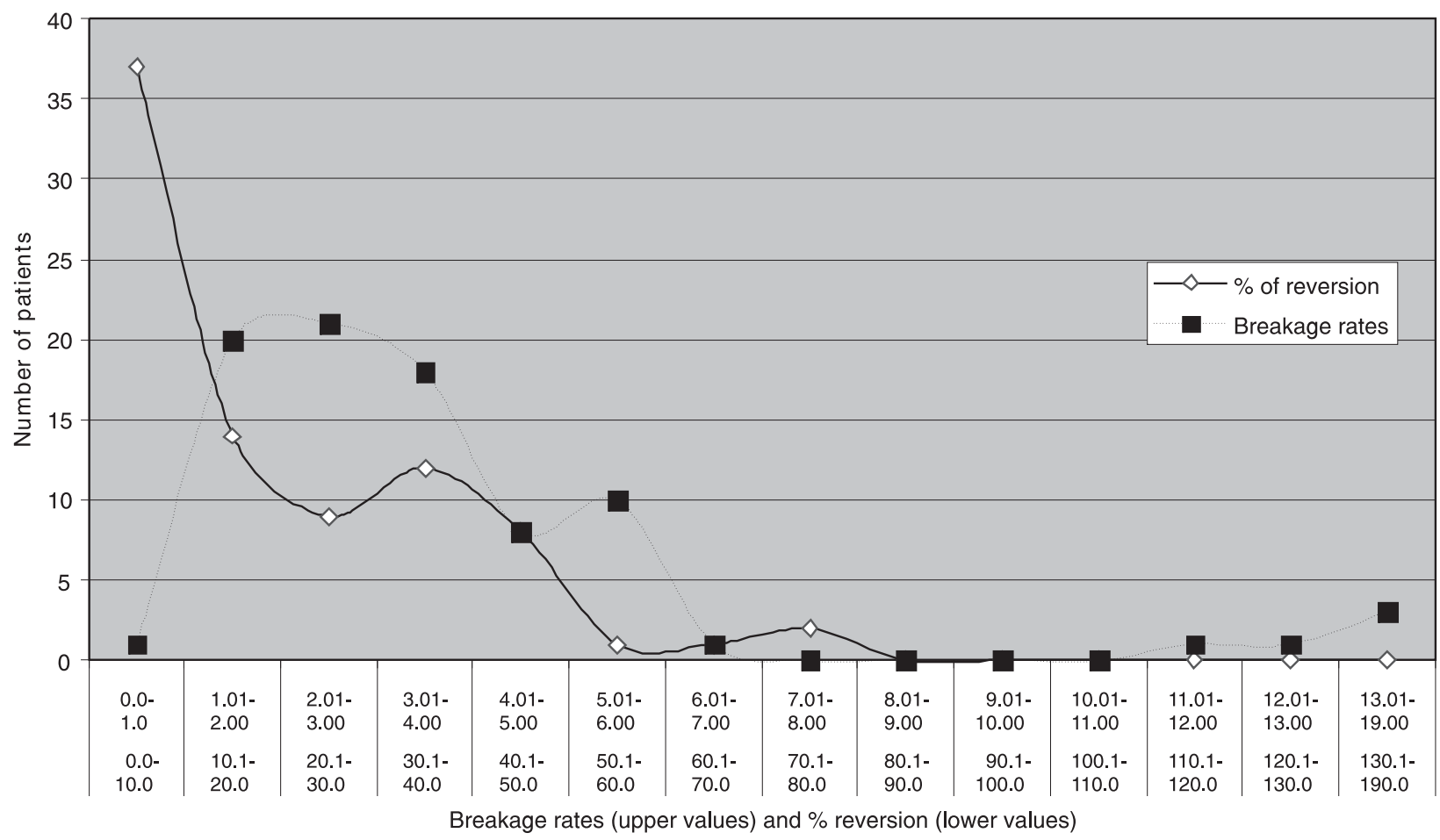

Figure 2. Distribution of patients according to diepoxybutane test parameters. 
Table 3. Comparison of FANCD2 Western blot phenotypes and the diepoxybutane (DEB) test parameters of Fanconi patients.

\begin{tabular}{lcc}
\hline FANCD2S/FANCD2L phenotypes & DEB test & $P$ \\
\hline & Median breakage rates & \\
FANCD2S+/FANCD2L+ $(\mathrm{N}=5)$ & 1.25 \\
FANCD2S+/FANCD2L- and FANCD2S-/FANCD2L- $(\mathrm{N}=79)$ & 3.04 \\
& Median \% of reversion & \\
FANCD2S+/FANCD2L+ $(\mathrm{N}=5)$ & $68 \%$ & 0.006 \\
FANCD2S+/FANCD2L- and FANCD2S-/FANCD2L- $(\mathrm{N}=79)$ & $16 \%$ &
\end{tabular}

FANCD2S = band corresponding to isoform $S$ (short or small) of the protein FANCD2. FANCD2L = band corresponding to isoform $\mathrm{L}$ (long or large) of monoubiquitinated FANCD2 protein.

divided into two groups according to the presence or absence of FANCD2 monoubiquitinated isoform for comparison of FANCD2 phenotypes to parameters of the DEB test (Table 3). When FANCD2 phenotypes were compared to the $\%$ of reversion, there was a significant difference between the two groups $(P=0.006)$. These data show that the presence of FANCD2L on DEB+ patients may be due to somatic mosaicism of hematopoietic cells. When FANCD2 phenotypes were compared to breakage rates, there was no significant difference between the two groups $(P=0.139)$. However, breakage rate is not an appropriate parameter to evaluate somatic reversion because it is based on the total number of breaks and not on the number of aberrant cells.

Evaluation of the Western blots for FANCD2 as a test for Fanconi anemia diagnosis, using DEB as the reference method, showed $94 \%$ sensitivity (79/84) and 100\% specificity (98/98).

The high specificity of the Western blot (100\%) leads to the conclusion that it is a reliable confirmatory test. The absence of FANCD2L is specific of Fanconi anemia while chromosome breaks may also be detected in other chromosomal breakage disorders, such as Nijemegen break-

\section{References}

1. Bagby GC, Alter BP. Fanconi anemia. Semin Hematol 2006; 43: 147-156.

2. Butturini A, Gale RP, Verlander PC, Adler-Brecher B, Gillio AP, Auerbach AD. Hematologic abnormalities in Fanconi anemia: an International Fanconi Anemia Registry study. Blood 1994; 84: 1650-1655.

3. Patel KJ, Joenje $\mathrm{H}$. Fanconi anemia and DNA replication repair. DNA Repair 2007; 6: 885-890.

4. Bogliolo M, Cabre O, Callen E, Castillo V, Creus A, Marcos R, et al. The Fanconi anaemia genome stability and tumour suppressor network. Mutagenesis 2002; 17: 529-538.

5. Medhurst $A L$, Laghmani el $H$, Steltenpool J, Ferrer $M$, Fontaine C, de Groot J, et al. Evidence for subcomplexes in age syndrome $(32,37)$. Results were inconclusive for $5.9 \%$ $(5 / 84)$ of the patients $(95 \% \mathrm{Cl}=0.89$ to $11.01 \%)$ due to a limitation of this method, which is based on the absence of FANCD2 monoubiquitinated isoform (FANCD2S+/ FANCD2L- or FANCD2S-/FANCD2L-). The presence of both FANCD2 bands on the Western blot requires further investigation to identify the disruption on the FA/BRCA pathway. Patients with a high number of reverted cells may also be missed by FANCD2 Western blot as discussed above.

The results of FANCD2 Western blot combined with those of the DEB test permitted the classification of most of the patients enrolled in this study in different FANCD2 phenotypes and facilitated the identification of the level of disruption of the FA/BRCA pathway.

\section{Acknowledgments}

We thank the support of St. Jude Children's Research Hospital International Outreach Program. We are grateful to Dr. Grover Bagby and the staff of the Cancer Institute at the Oregon Health and Science University, Portland, OR, USA, for their technical assistance in this study. the Fanconi anemia pathway. Blood 2006; 108: 2072-2080. 6. LoTen Foe Jr, Rooimans MA, Bosnoyan-Collins L, Alon N, Wijker M, Parker L, et al. Expression cloning of a cDNA for the major Fanconi anaemia gene, FAA. Nat Genet 1996; 14: 320-323.

7. Meetei AR, Levitus M, Xue Y, Medhurst AL, Zwaan M, Ling $\mathrm{C}$, et al. X-linked inheritance of Fanconi anemia complementation group B. Nat Genet 2004; 36: 1219-1224.

8. Strathdee CA, Gavish H, Shannon WR, Buchwald M. Cloning of cDNAs for Fanconi's anaemia by functional complementation. Nature 1992; 356: 763-767.

9. Howlett NG, Taniguchi T, Olson S, Cox B, Waisfisz Q, De Die-Smulders $C$, et al. Biallelic inactivation of BRCA2 in 
Fanconi anemia. Science 2002; 297: 606-609.

10. Timmers C, Taniguchi T, Hejna J, Reifsteck C, Lucas L, Bruun D, et al. Positional cloning of a novel Fanconi anemia gene, FANCD2. Mol Cell 2001; 7: 241-248.

11. de Winter JP, Leveille F, van Berkel CG, Rooimans MA, van Der Weel L, Steltenpool J, et al. Isolation of a cDNA representing the Fanconi anemia complementation group $\mathrm{E}$ gene. Am J Hum Genet 2000; 67: 1306-1308.

12. de Winter JP, Rooimans MA, van Der Weel $L$, van Berkel CG, Alon N, Bosnoyan-Collins L, et al. The Fanconi anaemia gene FANCF encodes a novel protein with homology to ROM. Nat Genet 2000; 24: 15-16.

13. de Winter JP, Waisfisz $Q$, Rooimans MA, van Berkel CG, Bosnoyan-Collins L, Alon N, et al. The Fanconi anaemia group G gene FANCG is identical with XRCC9. Nat Genet 1998; 20: 281-283.

14. Smogorzewska A, Matsuoka S, Vinciguerra $P$, McDonald ER III, Hurov KE, Luo J, et al. Identification of the FANCI protein, a monoubiquitinated FANCD2 paralog required for DNA repair. Cell 2007; 129: 289-301.

15. Levitus $M$, Waisfisz $Q$, Godthelp BC, de Vries $Y$, Hussain $S$, Wiegant WW, et al. The DNA helicase BRIP1 is defective in Fanconi anemia complementation group J. Nat Genet 2005; 37: 934-935.

16. Meetei AR, de Winter JP, Medhurst AL, Wallisch M, Waisfisz $Q$, van de Vrugt $H J$, et al. A novel ubiquitin ligase is deficient in Fanconi anemia. Nat Genet 2003; 35: 165-170.

17. Meetei AR, Medhurst AL, Ling $C, X$ ue $Y$, Singh TR, Bier $P$, et al. A human ortholog of archaeal DNA repair protein Hef is defective in Fanconi anemia complementation group M. Nat Genet 2005; 37: 958-963.

18. Reid S, Schindler D, Hanenberg H, Barker K, Hanks S, Kalb $\mathrm{R}$, et al. Biallelic mutations in PALB2 cause Fanconi anemia subtype FA-N and predispose to childhood cancer. Nat Genet 2007; 39: 162-164.

19. Xia B, Dorsman JC, Ameziane N, de Vries Y, Rooimans MA, Sheng $Q$, et al. Fanconi anemia is associated with a defect in the BRCA2 partner PALB2. Nat Genet 2007; 39: 159-161.

20. Levitus M, Rooimans MA, Steltenpool J, Cool NF, Oostra AB, Mathew CG, et al. Heterogeneity in Fanconi anemia: evidence for 2 new genetic subtypes. Blood 2004; 103: 24982503.

21. Shimamura A. Inherited bone marrow failure syndromes: molecular features. Hematology Am Soc Hematol Educ Program 2006; 63-71.

22. Garcia-Higuera I, Taniguchi T, Ganesan S, Meyn MS, Timmers C, Hejna J, et al. Interaction of the Fanconi anemia proteins and BRCA1 in a common pathway. Mol Cell 2001; 7: 249-262.

23. Taniguchi T, D'Andrea AD. Molecular pathogenesis of Fanconi anemia: recent progress. Blood 2006; 107: 42234233.

24. Meetei AR, Yan Z, Wang W. FANCL replaces BRCA1 as the likely ubiquitin ligase responsible for FANCD2 monoubiquitination. Cell Cycle 2004; 3: 179-181.

25. Gurtan AM, D'Andrea AD. Dedicated to the core: understanding the Fanconi anemia complex. DNA Repair 2006; 5:
$1119-1125$

26. Montes de Oca R, Andreassen PR, Margossian SP, Gregory $\mathrm{RC}$, Taniguchi $\mathrm{T}$, Wang $\mathrm{X}$, et al. Regulated interaction of the Fanconi anemia protein, FANCD2, with chromatin. Blood 2005; 105: 1003-1009.

27. Howlett NG, Taniguchi T, Durkin SG, D'Andrea AD, Glover TW. The Fanconi anemia pathway is required for the DNA replication stress response and for the regulation of common fragile site stability. Hum Mol Genet 2005; 14: 693-701.

28. Hussain S, Wilson JB, Medhurst AL, Hejna J, Witt E, Ananth $\mathrm{S}$, et al. Direct interaction of FANCD2 with BRCA2 in DNA damage response pathways. Hum Mol Genet 2004; 13: 1241-1248

29. Sims AE, Spiteri E, Sims RJ III, Arita AG, Lach FP, Landers T, et al. $\mathrm{FANCl}$ is a second monoubiquitinated member of the Fanconi anemia pathway. Nat Struct Mol Biol 2007; 14: 564567.

30. Auerbach AD, Adler B, Chaganti RS. Prenatal and postnatal diagnosis and carrier detection of Fanconi anemia by a cytogenetic method. Pediatrics 1981; 67: 128-135.

31. Auerbach $A D$, Rogatko $A$, Schroeder-Kurth TM. International Fanconi Anemia Registry: relation of clinical symptoms to diepoxybutane sensitivity. Blood 1989; 73: 391-396.

32. Shimamura A, Montes de OR, Svenson JL, Haining $N$, Moreau LA, Nathan DG, et al. A novel diagnostic screen for defects in the Fanconi anemia pathway. Blood 2002; 100: 4649-4654.

33. Soulier J, Leblanc T, Larghero J, Dastot $H$, Shimamura A, Guardiola $\mathrm{P}$, et al. Detection of somatic mosaicism and classification of Fanconi anemia patients by analysis of the FA/BRCA pathway. Blood 2005; 105: 1329-1336.

34. Hirschhorn R. In vivo reversion to normal of inherited mutations in humans. J Med Genet 2003; 40: 721-728.

35. Guardiola P, Pasquini R, Dokal I, Ortega JJ, van WeelSipman M, Marsh JC, et al. Outcome of 69 allogeneic stem cell transplantations for Fanconi anemia using HLA-matched unrelated donors: a study on behalf of the European Group for Blood and Marrow Transplantation. Blood 2000; 95: 422429.

36. Soares JF, Siqueira AL. Introdução à estatística médica. 2nd edn. Belo Horizonte: UFMG-Coopmed; 2002.

37. Nakanishi $\mathrm{K}$, Taniguchi $\mathrm{T}$, Ranganathan $\mathrm{V}$, New HV, Moreau LA, Stotsky M, et al. Interaction of FANCD2 and NBS1 in the DNA damage response. Nat Cell Biol 2002; 4: 913-920.

38. Wagner JE, Tolar J, Levran O, Scholl T, Deffenbaugh A, Satagopan J, et al. Germline mutations in BRCA2: shared genetic susceptibility to breast cancer, early onset leukemia, and Fanconi anemia. Blood 2004; 103: 3226-3229.

39. Gregory JJ Jr, Wagner JE, Verlander PC, Levran O, Batish $\mathrm{SD}$, Eide CR, et al. Somatic mosaicism in Fanconi anemia: evidence of genotypic reversion in lymphohematopoietic stem cells. Proc Natl Acad Sci U S A 2001; 98: 2532-2537.

40. Gross M, Hanenberg H, Lobitz S, Friedl R, Herterich S, Dietrich R, et al. Reverse mosaicism in Fanconi anemia: natural gene therapy via molecular self-correction. Cytogenet Genome Res 2002; 98: 126-135. 